\title{
Erratum
}

\section{Convection due to the selective absorption of radiation in a porous medium}

\author{
A.A. Hill \\ Department of Mathematical Sciences, University of Durham, DH1 3 LE, UK (e-mail: a.a.hill@durham.ac.uk) \\ Published online October 27, 2003 - (c) Springer-Verlag 2003
}

Continuum Mech. Thermodyn. (2003) 15: 451-462

Digital Object Identifier (DOI) 10.1007/s00161-003-0125-5

Published online September 12, 2003 - (C) Springer-Verlag 2003

Due to a technical error, the present contribution has been published twice in this journal. This article has already appeared in Volume 15 Number 3 (June 2003) and should be cited accordingly.

Springer-Verlag wishes to apologize to its customers and readers for this mistake. 